Provided for non-commercial research and education use. Not for reproduction, distribution or commercial use.

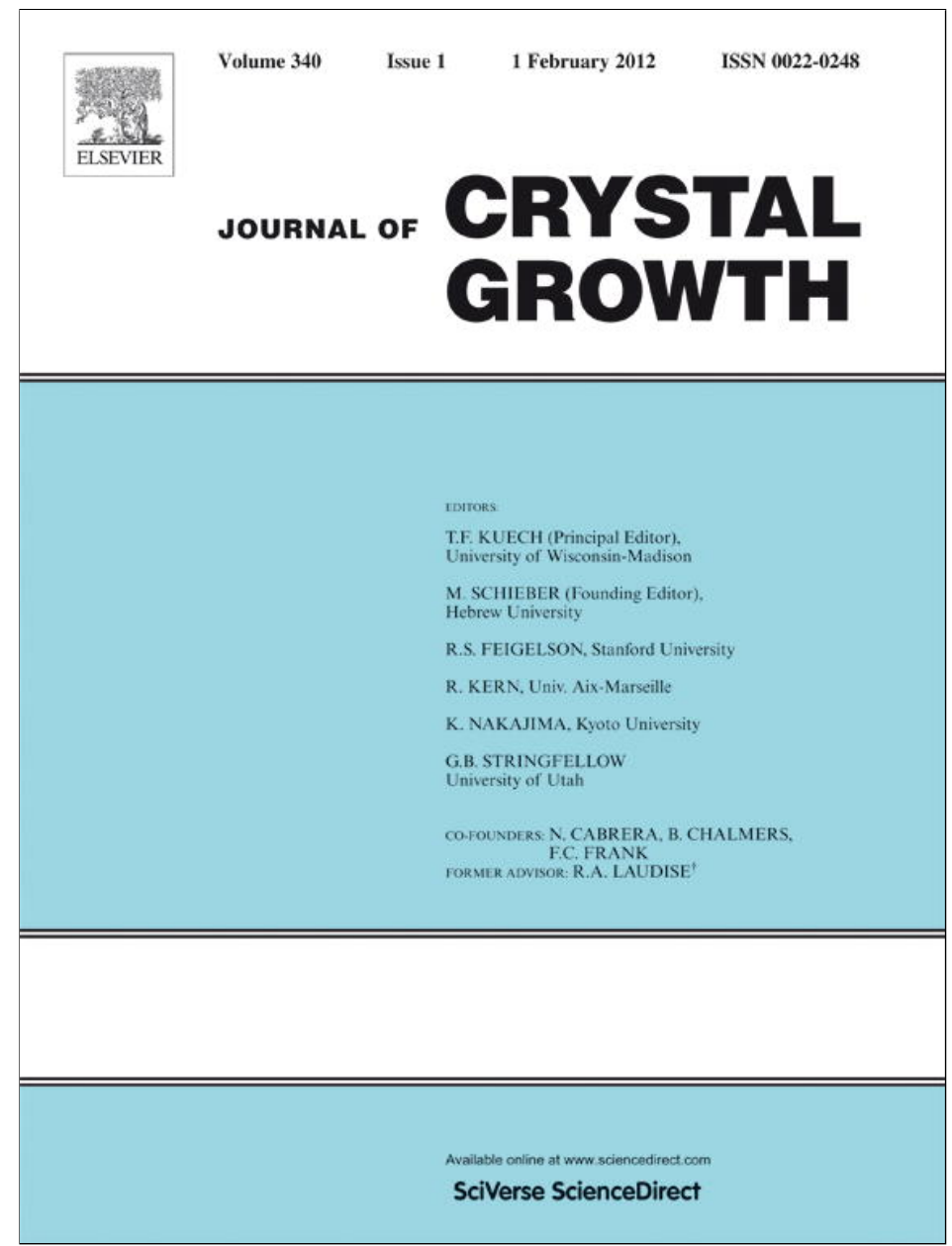

This article appeared in a journal published by Elsevier. The attached copy is furnished to the author for internal non-commercial research and education use, including for instruction at the authors institution and sharing with colleagues.

Other uses, including reproduction and distribution, or selling or licensing copies, or posting to personal, institutional or third party websites are prohibited.

In most cases authors are permitted to post their version of the article (e.g. in Word or Tex form) to their personal website or institutional repository. Authors requiring further information regarding Elsevier's archiving and manuscript policies are encouraged to visit:

http://www.elsevier.com/copyright 


\title{
Growth of diamond from fullerene C60 by spark plasma sintering
}

\author{
Faming Zhang ${ }^{\mathrm{a}, *}$, Furqan Ahmed ${ }^{\mathrm{b}, \mathrm{c}}$, Gerd Holzhüter ${ }^{\mathrm{a}}$, Eberhard Burkel ${ }^{\mathrm{a}}$ \\ a Institute of Physics, University of Rostock, August Bebel Strasse 55, Rostock 18055, Germany \\ ${ }^{\mathrm{b}}$ Department of Materials Science and Engineering, University of Erlangen-Nürnberg, Martens Strasse 5, Erlangen 91058, Germany \\ ${ }^{\mathrm{c}}$ Department of Metallurgical and Materials Engineering, University of Engineering and Technology, Lahore, Pakistan
}

\section{A R T I C L E I N F O}

\section{Article history:}

Received 28 October 2011

Received in revised form

30 November 2011

Accepted 1 December 2011

Communicated by P. Rudolph

Available online 8 December 2011

Keywords:

A1. X-ray diffraction

A2. Bulk crystal growth

B1. Diamond

B1. Fullerenes

\begin{abstract}
A B S T R A C T
The growth of diamond from fullerene C60 was studied by spark plasma sintering (SPS). The phases and microstructures were analyzed by Raman spectroscopy, Synchrotron X-ray, scanning electron microscopy and transmission electron microscopy. Experimental results show that 600 becomes unstable and can be directly transformed into diamond by SPS under a pressure of $50 \mathrm{MPa}$ at temperatures above $1150{ }^{\circ} \mathrm{C}$, without any catalyst being involved. Polycrystalline diamond crystals with sizes up to $250 \mu \mathrm{m}$ and transition rate about $30 \mathrm{vol} \%$ are obtained at SPS temperature of $1300{ }^{\circ} \mathrm{C}$. The mechanism indicates that the high fraction of $\mathrm{sp}^{3}$ hybrids in the fullerene C60 and the generated plasmas in the SPS lead to its transformation into diamond at such low temperatures and pressures. The transformation from C60 to diamond is a direct transition process with a structural reconstruction of carbon atoms without intermediate phases being involved.
\end{abstract}

(c) 2011 Elsevier B.V. All rights reserved.

\section{Introduction}

Due to its unique physical and chemical properties, fullerene C60 is a promising candidate substance for many novel applications in industry. Therefore, it is very important to deeply understand the stability and phase transformation behavior under extreme physical conditions. Duclos et al. [1] reported that the C60 molecules are extremely stable at room temperature, withstanding hydrostatic pressure of up to about $20 \mathrm{GPa}$. It is transformed irreversibly into a new hard carbon phase above hydrostatic pressure of $27 \mathrm{GPa}$ [2,3]. Under non-hydrostatic high pressures $(20 \pm 5 \mathrm{GPa})$, the $\mathrm{C} 60$ is unstable to collapse into a diamond phase at room temperature [4]. At high temperatures above $1500{ }^{\circ} \mathrm{C}, \mathrm{C} 60$ crystals are transformed into diamond in a pressure range of 9-15 GPa [5]. Nanocrystalline cubic diamond with crystallite sizes of 5-12 nm could be synthesized from fullerene $\mathrm{C} 60$ at $20 \mathrm{GPa}$ and $2000{ }^{\circ} \mathrm{C}$ using a multi-anvil apparatus [6]. Microcrystalline diamonds up to $6 \mu \mathrm{m}$ were produced from fullerenes C60 to C150 using a shock-wave synthesis under pressures ranged 24-40 GPa [7]. In general, it needs solely superhigh pressure or high pressure (in several GPa) and high temperature for the phase transition of $\mathrm{C60}$ to diamond.

The spark plasma sintering (SPS) is a field assisted sintering technique utilizing ON-OFF DC pulses to generate a pulsed electric field, which provides an extreme physical condition. The

\footnotetext{
*Corresponding author. Tel.: +49381 4986864; fax: +493814986862.

E-mail address: faming.zhang@uni-rostock.de (F. Zhang).
}

SPS has very broad applications for the preparation of conventional and new materials. However, it is a relatively new technique for the synthesis of diamonds. Our researches have shown that carbon nanotubes are unstable and can be converted into diamond without [8-10] or with metallic catalysts [11] under the pulsed electric field of the SPS. Our recent work has shown that C60 can be converted into diamond under the same SPS conditions as carbon nanotubes are converted to diamond $\left(1500{ }^{\circ} \mathrm{C}\right.$, $80 \mathrm{MPa}$ ) [12]. Since the $\mathrm{C} 60$ has a higher $\mathrm{sp}^{3}$ hybridization fraction than that of carbon nanotubes, it makes the transformation of $\mathrm{C60}$ into diamond easier. Therefore, it is postulated that the $\mathrm{C} 60$ may be able to increase the diamond size and transition rate in the SPS diamond synthetic method. In this study, the diamond growth from 600 was studied under the pulsed electric field of the SPS system to increase the size and transition rate of diamond. The spark plasma sintered carbon samples were analyzed using micro-Raman spectroscopy, Synchrotron X-ray, scanning electron microscopy (SEM) and transmission electron microscopy (TEM) techniques. Its phase transformation mechanism is also discussed.

\section{Materials and methods}

The fullerene $\mathrm{C60}$ was purchased from SES research, Houston, USA. The purity of the pristine C60 was claimed by the producer to be about $99.5 \%$. The pure $\mathrm{C} 60$ powders were pressed into a graphite die for SPS treatment to form disc-shaped samples. The SPS experiments were conducted using a Model of HP-D5 FCT 
spark plasma sintering system (FCT systeme $\mathrm{GmbH}$, Rauenstein, Germany) installed at the Tycho Sinter Lab in the University of Rostock, under an axial pressure of 50-80 MPa at temperatures of $1100-1500{ }^{\circ} \mathrm{C}$ in vacuum ( $<6 \mathrm{~Pa}$ ). A heating rate of $100 \mathrm{~K} / \mathrm{min}$ was used, and the sintering process lasted typically $20 \mathrm{~min}$. The applied direct current for SPS was about $1000 \mathrm{~A}$ with a pulse duration of $12 \mathrm{~ms}$ and an interval of $2 \mathrm{~ms}$ leading to disc-shaped samples with a diameter of $20 \mathrm{~mm}$ and a thickness of $5 \mathrm{~mm}$.

The sintered samples were etched in a solution of concentrated $\mathrm{H}_{2} \mathrm{SO}_{4}(90 \mathrm{vol} \%)$ and $\mathrm{HNO}_{3}(10 \mathrm{vol} \%)$ at room temperature for $12 \mathrm{~h}$. The etched samples were washed using de-ionized water repeatedly, and dried in an oven. The identification was performed with a Renishaw-2000 Laser Raman spectroscopy system with a He-Ne laser excited at $514 \mathrm{~nm}$ with a power density of $4.7 \mathrm{~mW}$ and a spot diameter of about $5 \mu \mathrm{m}$. Further identification was performed with a high-energy X-ray diffraction at beamline BW5 (DESY/HASYLAB Hamburger Synchrotron Laboratory) with a wavelength of $0.123984 \AA$ (100.0 keV). Scanning electron microscope (SEM, Zeiss Supra 25, Germany) and transmission electron microscope (TEM, Zeiss-Libra120, Germany) operating at $120 \mathrm{keV}$, were employed to characterize the starting materials and the products following the SPS treatment.

\section{Results and discussion}

Fig. 1(a) shows the TEM micrograph of the fullerene C60 powder with particle sizes from 40 to $100 \mathrm{~nm}$. There are some agglomerates in the particles. The inserted selected area diffraction pattern on a specific C60 particle indicates that the $C 60$ is a single crystal along the [110] direction. Fig. 1(b) shows the SEM micrograph of the $\mathrm{C} 60$ powder. The particle agglomerates are from nanometer to $4 \mu \mathrm{m}$.

Fig. 2(a) shows the Raman spectra of the raw C60 and the spark plasma sintered (SPSed) C60 samples after etching. The raw C60 shows a sharp peak that appeared at $1460 \mathrm{~cm}^{-1}$ and two weak broad peaks centered at 1568 and $1413 \mathrm{~cm}^{-1}$. Previous study [12] demonstrated that SPS processing of C60 with a pressure of $80 \mathrm{MPa}$ and a temperature of $1500{ }^{\circ} \mathrm{C}$ is leading to the formation of diamond. Hereby, the SPS pressure was reduced to $50 \mathrm{MPa}$. As expected, the cubic diamond peaks can also be detected at $1333 \mathrm{~cm}^{-1}$ in the Raman spectra taken for the samples SPS processed in the temperature range from 1150 to $1500{ }^{\circ} \mathrm{C}$. However, the diamond band of the samples sintered at $1150{ }^{\circ} \mathrm{C}$ is very broad having the lowest height. Its graphite band at $1568 \mathrm{~cm}^{-1}$ is at the same value as that of the raw C60. It indicates that there is only a small fraction of diamond in this $1150{ }^{\circ} \mathrm{C}$ SPSed sample. With an increase in temperature to 1200 , 1300 and $1500{ }^{\circ} \mathrm{C}$, the diamond band at $1333 \mathrm{~cm}^{-1}$ gets sharper and sharper, as well as the graphite band is shifted to a higher value of $1576 \mathrm{~cm}^{-1}$. The result of the $1300{ }^{\circ} \mathrm{C}$ SPSed C60 shows a Raman spectrum similar to the $1500{ }^{\circ} \mathrm{C}$ SPSed sample. The main

\section{a}

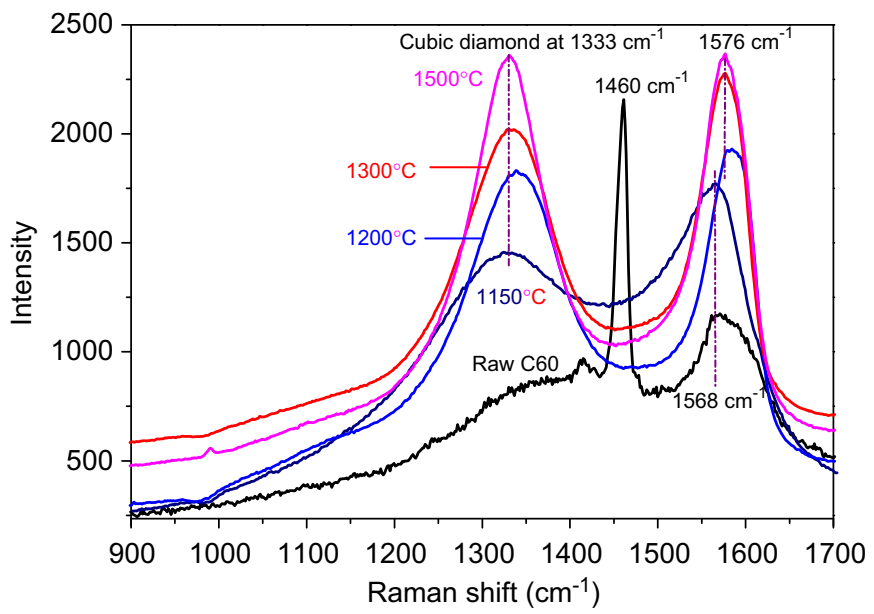

b

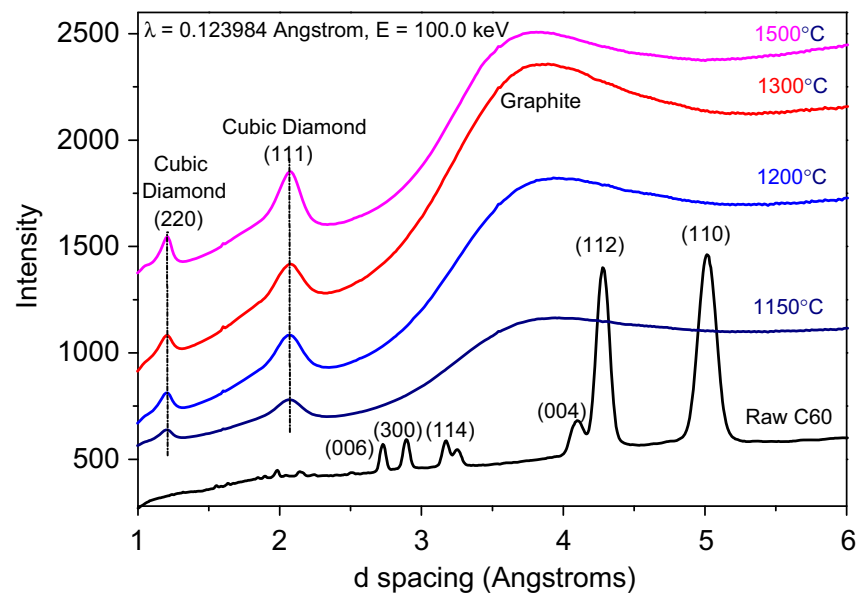

Fig. 2. Raman spectra (a) and synchrotron radiation-high energy X-ray diffraction patterns (b) of the raw C60 and the spark plasma sintered C60 at different temperatures under a pressure of $50 \mathrm{MPa}$.

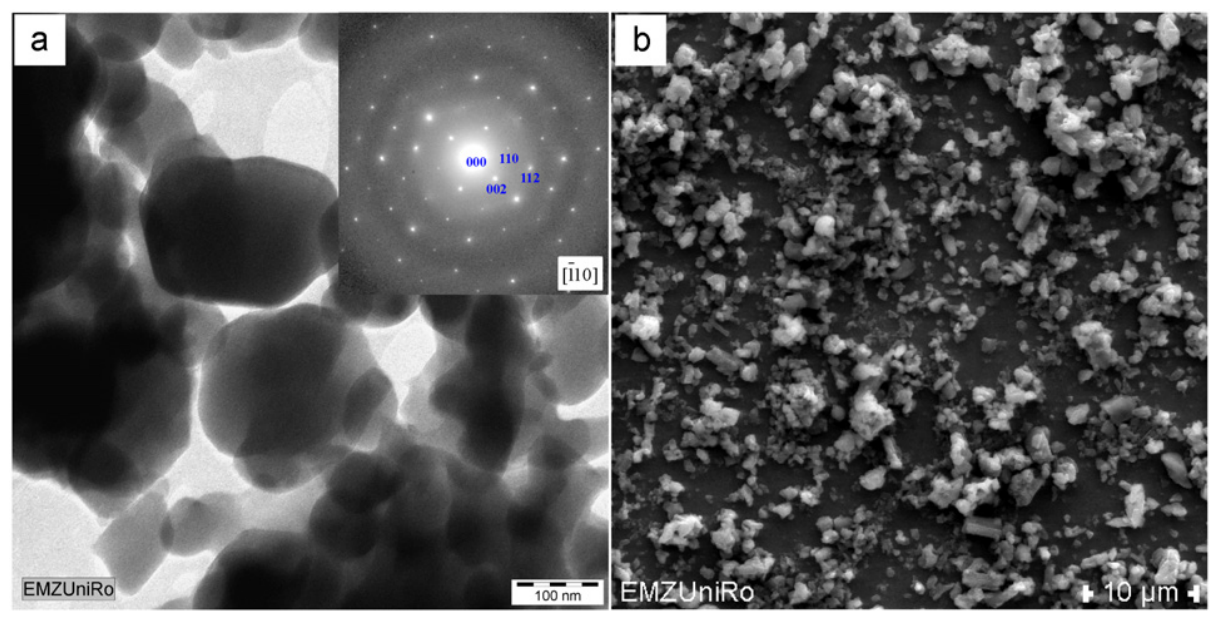

Fig. 1. TEM micrograph with inserted selected area diffraction pattern (a) and SEM micrograph of the raw fullerene C60 powder (b). 
peak in the pure $C 60$ spectrum at $1460 \mathrm{~cm}^{-1}$ disappears in all the spectra of the samples processed in the temperature range $1150-1500{ }^{\circ} \mathrm{C}$. This indicates that the C60 is completely transformed into diamond and graphite phases after SPS at above temperatures of $1150^{\circ} \mathrm{C}$. Fig. 2(b) shows the synchrotron radiation-high energy X-ray diffraction patterns of the raw $\mathrm{C} 60$ and the SPSed C60 samples after etching. In the $1150{ }^{\circ} \mathrm{C}$ sintered C60 sample, very weak diamond peaks at $d$ spacing of 2.06 and $1.26 \AA$ are found. The C60 after SPS at temperatures above $1200{ }^{\circ} \mathrm{C}$ show more shaped cubic diamond diffraction peaks at $d$ spacing of 2.06 and $1.26 \AA$ and broad graphite peaks. The synchrotron radiation is generated by the acceleration of ultrarelativistic charged particles and it can penetrate all the SPSed 660 pellets. The peaks of graphite are very broad indicating its amorphous structure. Amorphous graphite is the least graphitic of the graphite types where none of the common crystal faces are visible. The C60 diffraction peaks disappeared indicating the C60 has completely transformed into diamond and amorphous graphite phases after the SPS processing at temperatures from 1150 to $1500{ }^{\circ} \mathrm{C}$. The Raman and Synchrotron X-ray results confirmed the diamond formation in the C60 samples. However, the FWHMs of the diamond peaks in the Raman spectra and Synchrotron X-ray diffraction patterns are all broad. Such broad peaks are known to be a sign of fine diamond crystallites or highly detective nature of the crystals. It is calculated from the peak-area ratio in the Raman results that the fractions of the $\mathrm{sp}^{3}$ hybridized carbon in the final products are about $50 \mathrm{vol} \%$ in the samples of $1200-1500{ }^{\circ} \mathrm{C}$. As calculated from the peak-area ratio in the Synchrotron X-ray results, the fractions of the diamond in the final products are about $30 \mathrm{vol} \%$ in the samples processed at 1300 and $1500{ }^{\circ} \mathrm{C}$. Combining both of them, the transition rate of diamond from C60 is at least $30 \mathrm{vol} \%$ in the SPSed samples at 1300 and $1500{ }^{\circ} \mathrm{C}$.

Fig. 3 shows the SEM micrographs of the SPSed C60 samples after etching. In the $1150{ }^{\circ} \mathrm{C}$ SPSed sample, it noticed few small diamond particles, as marked by circles (Fig. 3a). Some diamond crystals with hexagonal, tetragonal or triangular shapes are found in Fig. 3(b) of the $1200{ }^{\circ} \mathrm{C}$ SPSed sample. The particle sizes of the diamond crystals are from tens of micrometers up to $200 \mu \mathrm{m}$, as marked by circles. The diamond crystals with perfect hexahedron shapes are clearly observed in the $1300{ }^{\circ} \mathrm{C}$ sintered sample (Fig. 3c). The diamond sizes range from 100 to $250 \mu \mathrm{m}$, and they are larger than those of the sample sintered at $1200^{\circ} \mathrm{C}$. Some fine diamond crystals are noticeable on one big diamond crystal. The micrographs of the $1500{ }^{\circ} \mathrm{C}$ sintered C60 sample show that the big diamond crystals are almost melted (Fig. 3d). There are many fine diamond crystals below $4 \mu \mathrm{m}$ on the big crystals (Fig. 3e). It is obvious that the diamond crystal sizes do not increase with the increase in temperature. A processing temperature of $1300{ }^{\circ} \mathrm{C}$ is the best for the phase transformation of C60 directly to diamond, according to this study. The particle size of the diamond crystals made from C60 is up to $250 \mu \mathrm{m}$. It is a very large size for such conversion without any catalyst being involved in the process.

The TEM micrograph of the $1200{ }^{\circ} \mathrm{C}$ spark plasma sintered C60 sample is shown in Fig. 4. Fig. 4(a) shows a big diamond crystal with some pure $\mathrm{C60}$ particles. The particle size of the C60 in this SPSed sample lies in the range of $40-100 \mathrm{~nm}$. It is identical to that of the pure C60 (Fig. 1a). The C60 particles are present with
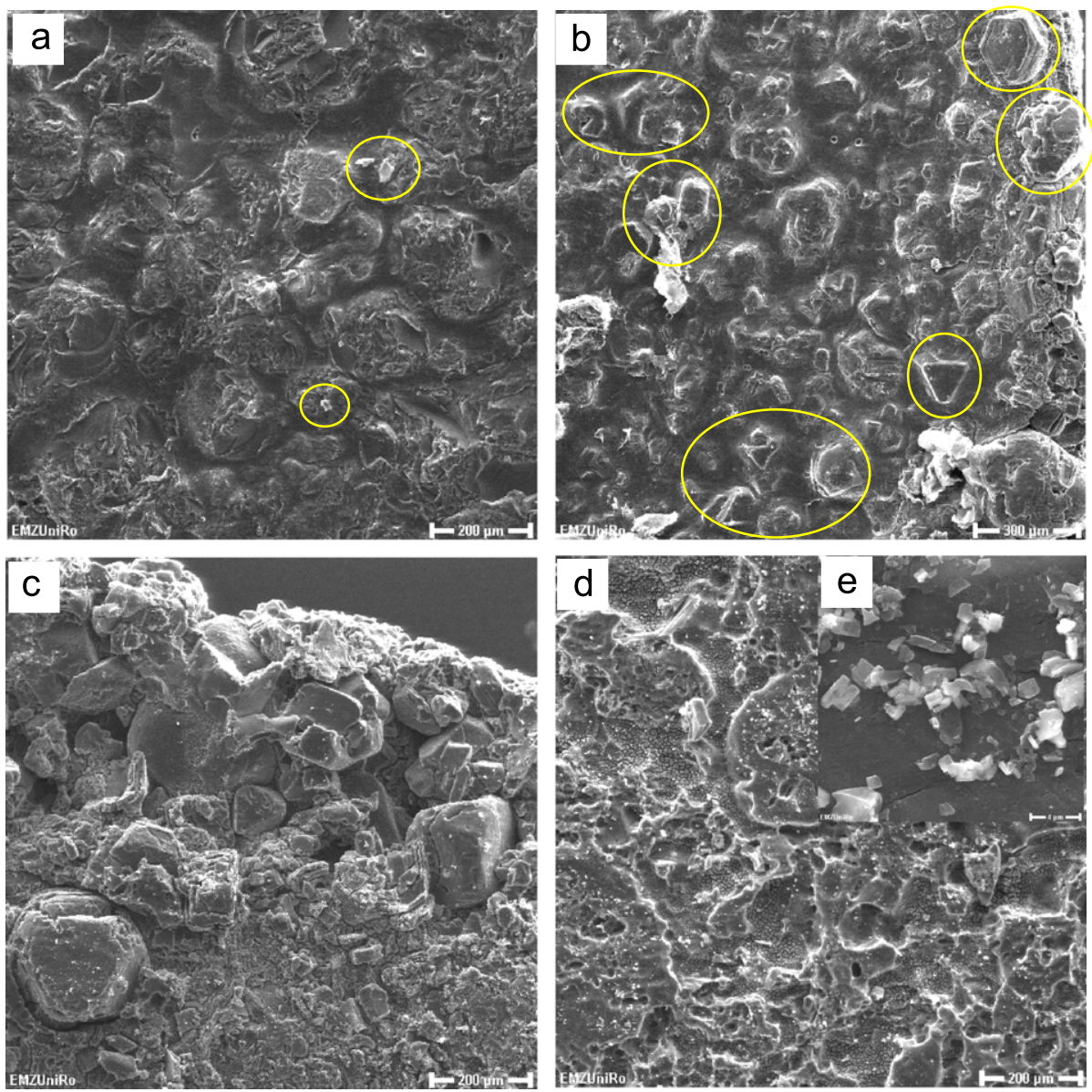

Fig. 3. SEM micrographs of spark plasma sintered C60 samples at $1150{ }^{\circ} \mathrm{C}$ (a), $1200{ }^{\circ} \mathrm{C}$ (b), $1300{ }^{\circ} \mathrm{C}$ (c) and $1500{ }^{\circ} \mathrm{C}$ (d, e) after etching, showing the growth of diamond crystals. 

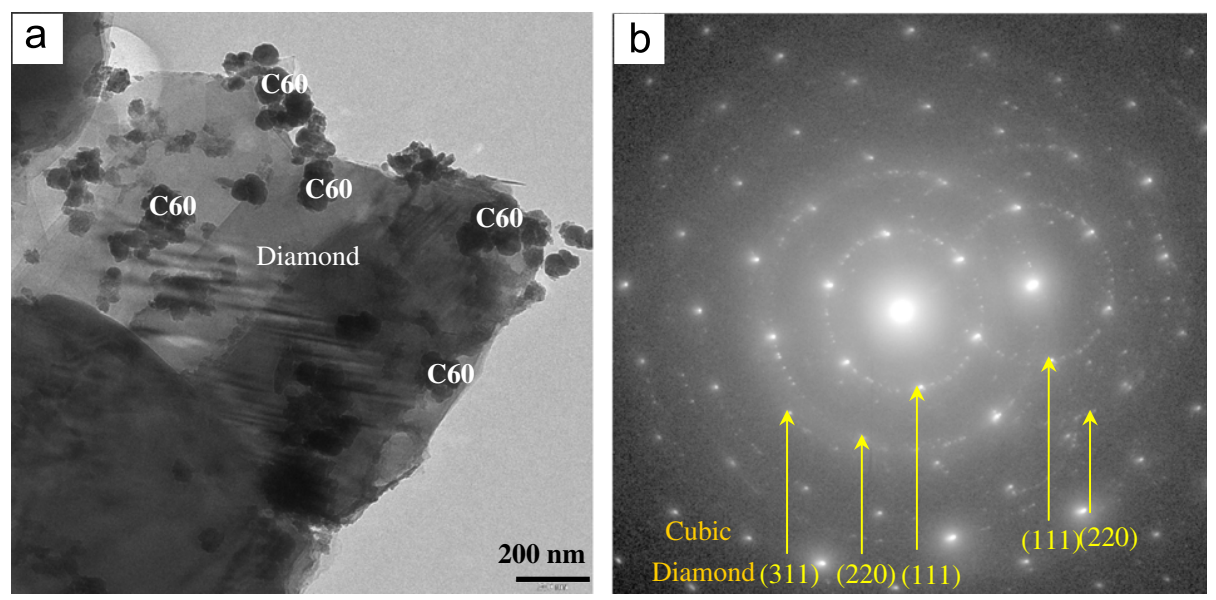

Fig. 4. TEM micrograph of a diamond crystal formed in the $1200{ }^{\circ} \mathrm{C}$ spark plasma sintered C60 sample (a) with the selected area diffraction pattern (b), exhibiting the polycrystalline diamonds.

the diamond crystal together. This indicates that the diamond is directly transformed from these $\mathrm{C} 60$ particles. The selected area diffraction pattern was diffraction rings were calculated and this confirmed that the diamonds are cubic polycrystals (Fig. 4b). It is noted that there are two sets of diffraction patterns indicating the presence of two cubic polycrystals in the selected area (Fig. 4b). No formation of an intermediate phase was observed for the C60 transformation into diamond in the TEM micrograph. The transformation from C60 to diamond seems to be a direct carbon transformation process with structural reconstruction without the production of any intermediate phase.

The Raman, Synchrotron X-ray, SEM and TEM identifications have confirmed the diamond formation in the C60 by the SPS at milder conditions. The diamond particle size and transition rate both increased using the $\mathrm{C} 60$ as carbon source for diamond synthesis. The experimental results validated the hypothesis in the introduction. Due to the high price of the $\mathrm{C60}$, conversion of C60 to diamond by SPS has more theoretical impact than its practical applications for the growth of diamond. For its practical use, this study suggests that the C60 may be able to be used as a doping catalyst to promote the diamond transitions. Vul et al. [13] have studied the effects of fullerene on the high-pressure high temperature synthesis of diamond from graphite and found that the fullerenes increased the percentage of graphite to diamond conversion by a factor of 1.8 and allowed the pressure and temperature of the synthesis to be decreased. Therefore, the application of $\mathrm{C} 60$ as one type of catalyst or doping catalyst for diamond synthesis in the SPS or other techniques has some practical prospects. The theoretical impact of the conversion of C60 into diamond by the SPS at such milder condition is very constructive. The carbon atoms in $\mathrm{C} 60$ are $\mathrm{sp}^{2}$ hybridized with a high fraction of $\mathrm{sp}^{3}$ hybridized structure due to an angular strain. It is a bit difficult to transform the planar $\mathrm{sp}^{2}$ structure to the diamond $\mathrm{sp}^{3}$ network. Our previous results confirmed that the graphite with pure $\mathrm{sp}^{2}$ structure cannot be converted to diamond in the SPS [12]. The C60 can be considered as a folded graphite sheet with the predominant $\mathrm{sp}^{3}$ hybridization in the pentagons. This makes the transformation of $\mathrm{C} 60$ into diamond easier. A dense assembly of 660 spheroids, where 48 out of 60 carbon atoms have quasi-tetrahedral coordination, is sterically fairly close to that of the diamond [1,4]. It implies that a small rearrangement of the atoms of C60 can result in the change of its structure. However, it still needs solely superhigh pressure or high pressure and high temperatures for the phase transition from C60 to diamond [1-6]. In the pulsed electric field of the SPS, the DC currents were passed through the graphite die and the C60 sample. The pulsed electric field in the SPS utilizes high currents up to thousands of ampere and low voltages up to $10 \mathrm{~V}$ eventually generating spark plasmas provides most of the energy for the diamond formation under such low temperatures and low pressure. Our previous research has proved the presence of plasmas during SPS of these conductive and high surface area nanocarbon materials [12]. Finally, the C60 gets unstable under such pulsed electric field and can be transformed into diamond at temperatures as low as $1150^{\circ} \mathrm{C}$. In other words, the mechanism for the conversion of $\mathrm{C} 60$ to diamond owns to the special structure of the C60 and the unique SPS technique.

\section{Conclusions}

Fullerene C60 is unstable and can be transformed into crystalline diamond by spark plasma sintering under a pressure of $50 \mathrm{MPa}$ above temperatures of $1150{ }^{\circ} \mathrm{C}$ without any catalysts being involved. Well-defined diamonds with particle sizes up to $250 \mu \mathrm{m}$ and transition rate about $30 \mathrm{vol} \%$ are obtained at $1300^{\circ} \mathrm{C}$ and no further growth in particle size is seen beyond this temperature. The mechanism analysis indicates that the high $\mathrm{sp}^{3}$ hybrid fraction in the $\mathrm{C} 60$ and the generated plasmas in the pulsed electric field lead to its transformation to diamond. It is a direct transition process from C60 to diamond with a structural reconstruction of carbon atoms without intermediate phases being involved.

\section{Acknowledgment}

Financial support from the DFG-Deutschen Forschungsgemeinschaft (German Research Foundation) with Grant no. BU 547/10-1 and DESY Hasylab Project with Grant No. II-20090264 are acknowledged.

\section{References}

[1] S.J. Duclos, K. Brister, R.C. Haddon, A.R. Kortan, F.A. Thiel, Nature 45 (1991) 380-382.

[2] F. Mosshary, N.H. Chen, L.F. Silvera, C.A. Brown, H.C. Dorn, M.S. de Veies, D.S. Bethune, Physical Review Letters 69 (1992) 466-469.

[3] V. Brazhkin, A. Lyapin, New Diamond and Frontier Carbon Technology 14 (5) (2004) 259-278.

[4] M.N. Regueiro, P. Monceau, J.L. Hodeau, Nature 355 (1992) 237-239.

[5] V.D. Blank, S.G. Buga, N.R. Serebryanaya, G.A. Dubitsky, S.N. Sulyanov, M.Y. Popov, V.N. Densisov, A.N. Ivlev, B. Mavrin, Physics Letters A 220 (1996) 149-157. 
[6] N. Dubrovinskaia, L. Dubrovinsky, F. Langenhorst, S. Jacobsen, C. Liebske, Diamond and Related Materials 14 (2005) 16-22.

[7] O.G. Epanchintsev, A.S. Zubchenko, A.E. Korneyev, V.A. Simonov, Journal of Physics and Chemistry of Solids 158 (11) (1997) 1785-1788.

[8] F. Zhang, J. Shen, J. Sun, D.G. McCartney, Carbon 43 (6) (2005) 1254-1258.

[9] J. Shen, F.M. Zhang, J.F. Sun, Y.Q. Zhu, G. McCartney, Nanotechnology 17 (2006) 2187-2191.
[10] F. Zhang, J. Shen, J. Sun, D.G. McCartney, Carbon 44 (2006) 3136-3138.

[11] F. Zhang, M. Adam, E. Otterstein, E. Burkel, Diamond and Related Materials 20 (2011) 853-858.

[12] F. Zhang, C. Mihoc, F. Ahmed, C. Latte, E. Burkel, Chemical Physics Letters 510 (2011) 109-114.

[13] A.Ya. Vul, V.M. Davidenko, S.V. Kidalov, S.S. Ordan'yan, V.A. Yashin, Technical Physics Letters 27 (2001) 384-386. 